\title{
Repercussões extra-esofágicas da Doença do Refluxo Gastroesofágico (DRGE) sob o ponto de vista da otorrinolaringologia
}

\author{
Extra esophageal repercussions of Gastroesophageal Reflux Disease (GERD) from the \\ point of view of otorhinolaryngology
}
Repercusiones extraesofágicas de Enfermedad por Reflujo Gastroesofágico (ERGE) desde el punto de vista de otorrinolaringología

Jemima Ferreira Coelho ${ }^{1 *}$, Laura Pires Ligeiro', Filipe de Deus Tozani ${ }^{1}$, Henrique Santos Goulart do Amaral ${ }^{1}$, Maria Luísa Vieira de Lima Brito', Fernanda Souto Carvalho', Juliana Magalhães Vieira Assunção ${ }^{1}$, Riquelme Romero Leal Portela', Ana Silvia Menezes Bastos ${ }^{1}$.

\section{RESUMO}

Objetivo: Sintetizar a problemática da Doença do Refluxo Gastroesofágico (DRGE) e suas repercussões clínicas extra-esofágicas na otorrinolaringologia. Métodos: É uma revisão de literatura narrativa de natureza exploratória. As etapas deconstrução dessa revisão foram: selecionar o tema e a questão de pesquisa, buscar artigos nas bases de dados digitais no período de 2015 a 2021, aplicar critérios de inclusão e exclusão na amostra, além da discussão dos resultados apresentados pelos artigos. Resultados: A patologia apresenta sinais e sintomas clínicos extra-esofágicos importantes como: tosse, rouquidão, laringite, erosão dentária, apneia obstrutiva do sono, sinusite e ou rinite crônica, dentre outros dentro da otorrinolaringologia. Também foi abordado o tratamento medicamentoso da doença e sua ef etividade na resolução desses sintomas. Além de medicamentos como inibidores de bomba de prótons, a mudança no estilo de vida é fundamental. Considerações finais: É muito importante para o médico entender que a DRGE gera sintomas otorrinolaringológicos importantes e que impactam diretamente na qualidade de vida do paciente, e que devem ser levados em conta na sua terapêutica para que esta seja ef etiva.

Palavras-chave: Doença do refluxo gastroesofágico, Otorrinolaringologia, Tratamento medicamentos.

\begin{abstract}
Objective: To synthesize the problem of Gastroesophageal Reflux Disease (GERD) and its extra-esophageal clinical repercussions in otorhinolaryngology. Methods: It is an exploratory narrative literature review. The construction steps of this review were: selecting the theme and research question, searching for articles in digital databases from 2015 to 2021, applying inclusion and exclusion criteria in the sample, in addition to discussing the results presented by the articles. Results: The pathology presents important extra-esophageal clinical signs and symptoms such as: cough, hoarseness, laryngitis, dental erosion, obstructive sleep apnea, sinusitis and or chronic rhinitis, among others within otorhinolaryngology. The drug treatment of the disease and its effectiveness in resolving these symptoms were also addressed. In addition to medications such as proton pump inhibitors, lifestyle change is critical. Final considerations: It is very important for the physician to understand that GERD generates important otorhinolaryngological symptoms that directly impact the patient's quality of life, and that they must be taken into account in their treatment for it to be effective.
\end{abstract}

Key words: Gastroesophageal reflux disease, Otorhinolaryngology, Drug treatment.

\footnotetext{
${ }^{1}$ Universidade de Vassouras (UV), Vassouras - RJ.

*E-mail: mimaferreira13@gmail.com
}

SUBMETIDO EM: 11/2021 


\section{RESUMEN}

Objetivo: Sintetizar el problema de la Enfermedad por Reflujo Gastroesofágico (ERGE) y sus repercusiones clínicas extraesofágicas en otorrinolaringología. Métodos: Es una revisión de literatura narrativa exploratoria. Los pasos de construcción de esta revisión fueron: seleccionar el tema y la pregunta de investigación, buscar artículos en bases de datos digitales de 2015 a 2021, aplicar criterios de inclusión y exclusión en la muestra, además de discutir los resultados presentados por los artículos. Resultados: La patología presenta importantes signos y síntomas clínicos extraesofágicos como: tos, ronquera, laringitis, erosión dental, apnea obstructiva del sueño, sinusitis y rinitis crónica, entre otros dentro de la otorrinolaringología. También se abordaron el tratamiento farmacológico de la enfermedad y su eficacia para resolver estos síntomas. Además de los medicamentos como los inhibidores de la bomba de protones, el cambio de estilo de vida es fundamental. Consideraciones finales: Es muy importante que el médico comprenda que la ERGE genera importantes síntomas otorrinolaringológicos que impactan directamente en la calidad de vida del paciente, y que deben ser tomados en cuenta en su tratamiento para que sea efectivo.

Palabras clave: Enfermedad por reflujo gastroesofágico, Otorrinolaringología, Tratamiento farmacológico.

\section{INTRODUÇÃO}

A Doença do Refluxo Gastroesofágico (DRGE) é uma condição clínica desenvolvida na presença de um fluxo retrógrado do conteúdo gástrico de volta para o esôfago. Trata-se de uma patologia de alta prevalência e que está diretamente relacionada a hábitos de vida não saudáveis, tais como: consumo de alimentos gordurosos e processados, alcoolismo, tabagismo, dentre outros. Alguns mecanismos envolvidos na patogênese de DRGE são referentes a disfunção do esfíncter esofágico inferior que, uma vez prejudicada, leva a relaxamentos transitórios, podendo estar associada à hérnia de hiato, defesa da mucosa esofágica prejudicada contra o refluxo gástrico e defeitos da motilidade esofágica. Devido a isso, a doença pode se manifestar de três formas: típica com azia e regurgitação, forma atípica e forma extra-esofágica (ANTUNES C, et al., 2021).

A faringe representa uma comunicação anatômica direta entre o sistema digestivo e o respiratório, estende-se da base do crânio até a margem inferior da cartilagem cricóidea, a nível da margem inferior da sexta vértebra cervical, a partir de onde se torna contínua com o esôfago na junção faringoesofágica. Essa junção apresenta-se como uma constricção produzida pela parte cricofaríngea do músculo constritor inferior da faringe, que corresponde ao esfíncter esofágico superior. A incompetência deste esfíncter é fundamental para a ocorrência do refluxo laring of aríngeo. Além disso, a faringe pode ser dividida em nasofaringe, com função respiratória, orofaringe que está envolvida no trânsito do bolo alimentar e laringofaringe que é responsável por impedir o refluxo para as vias aéreas (DURAZZO M, et al., 2020).

É válido ressaltar a importância das repercussões extra-esofágicas da DRGE para a otorrinolaringologia. Analisando a relação entre a orofaringe e o trato respiratório, torna-se evidente que o conteúdo oriundo do estômago pode durante uma regurgitação, atingir tanto as vias aéreas superiores quanto pode ter acesso as vias aéreas inferiores por meio da broncoaspiração (JUNAID M, et al., 2020)

Dentre as repercussões extra-esofágicas, têm-se aquelas das vias aéreas superiores como: laringite crônica, sinusite crônica. Como manifestações nas vias aéreas inferiores temos: tosse crônica, episódios de asfixia, pneumonite por aspiração e crises de asma (AKINOLA MA, et al., 2020).

Por esse motivo, são propostos dois mecanismos para tentar explicar a fisiopatologia do surgimento dessas manifestações. O primeiro seria por uma via direta, que consiste em uma injúria direta do conteúdo gastroesofágico à mucosa respiratória, e um segundo que seria uma via indireta, na qual o conteúdo gástrico regurgitado no esôfago estimula um arco reflexo via nervo vago que gera respostas nas vias aéreas, como 0 broncoespasmo (DURAZZO M, et al., 2020).

Outra entidade clínica associada é o Refluxo Laringofaríngeo (RLF), que consiste em uma condição inflamatória dos tecidos do trato aerodigestivo superior relacionada ao ef eito direto e indireto do refluxo do 
conteúdo gastroduodenal, que induz alterações morfológicas, sendo os principais sintomas associados: globus faríngeo, pigarro, excesso de muco da garganta ou gotejamento pós-nasal (DAI YF, et al., 2020).

Além disso, existe a hipótese de que a pepsina possa estimular a infiltração de células inflamatórias na mucosa laríngea, criando um microambiente inflamatório capaz de promover dano oxidativo às células epiteliais, acelerando a formação e o desenvolvimento de pólipos de pregas vocais (DAIYF, et al., 2020).

Com relação ao diagnóstico e ao tratamento desses pacientes, deve-se ressaltar que o diagnóstico de RLF ainda é difícil, visto que os sintomas e achados são porvezes inespecíficos. A abordagem diagnóstica mais validada para RLF é o hypopharyngeal-esophageal MII-pH, e a forma de tratamento mais utilizada no Brasil é o uso diário de Inibidores de Bomba de Prótons (IBPs) juntamente com mudanças nos hábitos de vida, que são recomendadas pela maioria dos otorrinolaringologistas brasileiros (LECHIEN JR, et al., 2020).

Tendo em vista a alta prevalência da DRGE bem como o impacto negativo da doença na qualidade de vida dos indivíduos, o presente estudo teve como objetivo analisar as manifestações extra-esofágicas da DRGE e o seu impacto na qualidade de vida do paciente, além das possibilidades terapêuticas existentes.

\section{MÉTODOS}

Trata-se de uma revisão de literatura narrativa de natureza exploratória, com abordagem qualitativa, cuja análise dos dados coletados foi realizada através da análise de discurso. Os estágios de confecção que se sucederam foram: escolha do tema e questão de pesquisa, busca dos artigos nas bases de dados digitais; posteriormente foram estabelecidos os critérios de inclusão e exclusão para os estudos e em seguida realizou se uma análise com discussão dos resultados apresentados pelos periódicos. As bases de dados digitais utilizadas foram: National Library of Medicine (PubMed), Literatura Latino-americana e do Caribe em Ciências da Saúde (LILACS) e Scientific Electronic Library Online (SciELO).

No PubMed, os artigos foram realizados três pesquisas, sendo utilizado a primeira pesquisa os descritores "extraesophageal manifestations" e "gastro esophageal reflux disease". Na segunda busca os descritores foram: "gastro esophageal reflux disease" and "otorhinolaryngology", e para um maior aprofundamento sobre o tema, foi feito uma terceira pesquisa com o descritor "pharyngolaryngeal reflux disease". Já na base de dados LILACS e SciELO, os artigos foram selecionados utilizando os descritores "extraesophageal manifestations" e "gastroesophageal reflux disease".

A busca incorporou artigos em português, inglês e espanhol, o que resultou em uma amostra de 1797 artigos no PubMed, 15 artigos no LILACS e 5 artigos no SciElo. Após a aplicação de uma filtragem temporal de 2015 a 2021 restaram 734 artigos (PubMed), 3 artigos (LILACS) e 2 artigos (SciELO), dos quais foram excluídas as duplicatas, os artigos cujos descritores não estavam de acordo com a temática principal, ou seja, não abordavam as repercussões otorrinolaringológicas da DRGE. De todos os arquivos restantes, foram utilizados os artigos de maior relevância, ficando ao todo 34 artigos como arcabouço teórico.

A análise de conteúdo aconteceu em três etapas de seleção. A primeira teve a procura pelos descritores propostos. A segunda foi por meio do título e resumo e a terceira pela qualificação dos artigos. Para a primeira etapa houve a seleção dos textos sobre a temática. Na segunda, houve a leitura e enquadramento de quais seriam viáveis para o objetivo principal. E na terceira triagem, os artigos foram lidos e selecionados conforme a proposta deste estudo.

De acordo com a Figura 1, nota-se os resultados das pesquisas feitas nas bases de dados utilizadas, após ser aplicado o filtro relacionado ao tempo (de 2015 a 2021) em cada uma delas. Também cita os critérios de inclusão e exclusão utilizados nas buscas, resultando em 27 artigos. 
Figura 1 - Fluxograma da seleção dos estudos para esta revisão.

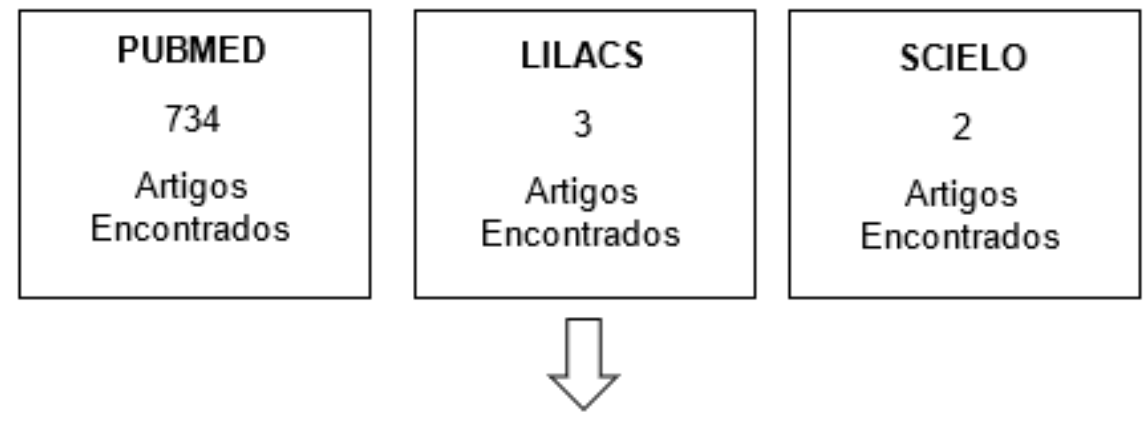

Critérios de Inclusão: artigos baseados em consensos e diretrizes sobreDRGE que abordaram o diagnóstico e tratamento da patologia bem como suas possíveis repercussões para a qualidade de vida do paciente.

Critérios de Exclusão: artigos que tangenciam o tema ou que os descritores não estavam correlacionados a proposta de pesquisa bem como as duplicatas.

Após aplicação dos critérios citados acima obteve-se um total de 34 artigos

Fonte: Coelho JF, et al., 2021.

\section{RESULTADOS E DISCUSSÃO}

À princípio, partindo da seleção de 27 artigos com descritores específicos e verificados relacionados ao tema do trabalho, cada um deles foi arquivado para estudo, consulta e análise crítica. Seguiu por um reconhecimento minucioso desse material e por uma leitura detalhada a fim de selecionar as partes ess enciais para a temática e escrita do artigo.

Os artigos variam entre 2015 a 2021 sendo de origem brasileira, americana e latina. O estudo do material de base pode ser visto que apesar dos mais variados perfis epidemiológicos envolvendo a patologia circula entre sua maioria um padrão para os sintomas e para o tratamento, apesar necessitar de muito estudo.

Durante o estudo do material coletado, foi constatado um padrão de sintomas clínicos extra-esofágicos apresentados pela maioria dos pacientes nos atendimentos de otorrinolaringologia sendo as manifestações mais frequentes da DRGE a tosse, a laringite, asma e lesão dentária. Em um panorama geral os estudos mostraram que a tosse ocorre nos primeiros 2 minutos da ocorrência de refluxo, isso se deve a uma agressão causada pelo ácido clorídrico que leva a uma deficiência de movimentos peristálticos e a uma sensi bilização dos receptores tussígenos (ANTUNES C, et al., 2021).

Vale também ressaltar que os hábitos de vida associado com fatores genéticos são muito importantes para o desenvolvimento do DRGE. Logo, a presença de padrão alimentar não equilibrado com grand e consumo calórico, associado ao sedentarismo e a obesidade tornam as pessoas mais predispostas à ocorrência do refluxo (AKINOLA MA, et al., 2020).

Dessa forma, depreende se que os dados obtidos por meio dos artigos eleitos se enquadram afirmando que apesar das divergências existe uma natureza em comum entre eles, tornando os extremamente relevantes para atual conjuntura em que vivemos o que é favorecido através das informações dispostas no Quadro 1, para título de pesquisa e esclarecimento do que foi exposto. 
Quadro 1 - Principais achados segundo os critérios de inclusão e exclusão estabelecidos pela revisão

\begin{tabular}{|c|c|c|c|}
\hline Título & Autor / Ano & Objetivos / Resultados & Conclusão \\
\hline $\begin{array}{l}\text { Doença do refluxo gastroesofágico: } \\
\text { prevalência e manifestações extra } \\
\text { esofágicas entre estudantes de } \\
\text { graduação no sudoeste da Nigéria }\end{array}$ & Akinola MA, et al. (2020). & $\begin{array}{c}\text { Afirmou os sintomas e os indícios extra } \\
\text { esofágicos dos alunos da Universidade de } \\
\text { Babcock. }\end{array}$ & $\begin{array}{l}\text { Observou a idade como o único } \\
\text { preditivo de DRGE entre os alunos. Os } \\
\text { sinais extra esofágicos são comuns } \\
\text { entre eles. }\end{array}$ \\
\hline Doença do refluxo gastroesofágico & Antunes C, et al. (2021). & $\begin{array}{c}\text { É uma patologia clinicamente refratária e está } \\
\text { cada vez mais comum que resulta em alto } \\
\text { gasto para a saúde, além de af etar a } \\
\text { qualidade de vida. }\end{array}$ & $\begin{array}{l}\text { Pacientes com DRGE com sintomas } \\
\text { típicos geralmente são tratados com os } \\
\text { cuidados primários. Já os refratários } \\
\text { são encaminhados para o médico } \\
\text { especialista. }\end{array}$ \\
\hline $\begin{array}{l}\text { Síndrome da apnéia obstrutiva do } \\
\text { sono e doença do refluxo } \\
\text { gastroesofágico: a importância da } \\
\text { obesidade e gênero }\end{array}$ & Basoglu OK, et al. (2015). & $\begin{array}{c}\text { Tinha por objetivo correlacionar a SAOS com } \\
\text { a obesidade. Mostrou como a obesidade e o } \\
\text { gênero são fatores de risco importantes } \\
\text { para SAOS. }\end{array}$ & $\begin{array}{c}\text { Ficou claro que para o tratamento da } \\
\text { SAOS deve incluir mudanças no estilo } \\
\text { de vida. E que isso provou reduzir de } \\
\text { forma significativa os níveis de pressão } \\
\text { arterial. }\end{array}$ \\
\hline $\begin{array}{l}\text { Os sintomas persistentes à terapia } \\
\text { com inibidores da bomba de prótons } \\
\text { são devidos à doença do refluxo } \\
\text { gastroesofágico refratário ou a outros } \\
\text { distúrbios? }\end{array}$ & AZZAM RS (2018). & $\begin{array}{c}\text { Produzir uma revisão de literatura atual, } \\
\text { observando as causas, diagnósticos e a } \\
\text { terapêutica dos casos com suspeita de refluxo. }\end{array}$ & $\begin{array}{c}\text { O diagnóstico e o tratamento são } \\
\text { próprios para cada uma dessas } \\
\text { patologias. }\end{array}$ \\
\hline $\begin{array}{l}\text { Diagnóstico de DRGE em } \\
\text { manifestações típicas e atípicas }\end{array}$ & Cesário S, et al. (2018). & $\begin{array}{c}\text { A patologia deve ser uma hipótese de } \\
\text { diagnóstico quando os doentes apresentarem } \\
\text { os sintomas atípicos e o diagnóstico } \\
\text { diferencial já for excluído por outro } \\
\text { especialista. }\end{array}$ & $\begin{array}{c}\text { DRGE é uma patologia profunda e de } \\
\text { origem complexa que dificulta um } \\
\text { diagnóstico direto. }\end{array}$ \\
\hline $\begin{array}{c}\text { Situação atual da doença do refluxo } \\
\text { gastroesofágico: diagnóstico e } \\
\text { tratamento }\end{array}$ & Chuang TW, et al. (2017). & $\begin{array}{l}\text { Aprofundar a melhoria na busca pelo } \\
\text { diagnóstico e pelo tratamento. AO raciocínio } \\
\text { clínico como peça fundamental para } \\
\text { investigação do DRGE }\end{array}$ & $\begin{array}{l}\text { O manejo desta doença requer uma } \\
\text { abordagem complexa. A terapia de } \\
\text { manutenção da DRGE após o uso de } \\
\text { drogas anti secretoras deve ser } \\
\text { monitorada continuamente. }\end{array}$ \\
\hline
\end{tabular}




\begin{tabular}{|c|c|c|c|}
\hline Título & Autor / Ano & Objetivos / Resultados & Conclusão \\
\hline $\begin{array}{c}\text { A busca pelo Graal: uma corrida para } \\
\text { a supressão de ácido }\end{array}$ & Cossío SS, et al. (2019). & $\begin{array}{c}\text { Analisar os mecanismos de ação, } \\
\text { farmacocinética e a tecnologia para melhorar o } \\
\text { desempenho dos IBP na DRGE. O estudo da } \\
\text { farmacocinética ajudou a diminuir o uso de } \\
\text { IBP. }\end{array}$ & $\begin{array}{l}\text { A melhoria das ações dos fármacos } \\
\text { geram resultados promissores para o } \\
\text { tratamento da DRGE, diminuindo o uso } \\
\text { de IBPs e o tempo de tratamento. }\end{array}$ \\
\hline $\begin{array}{l}\text { Associação de pepsina e danos de } \\
\text { DNA no refluxo laringofaríngeo } \\
\text { relacionado a pólipos de prega }\end{array}$ & Dai FY, et al. (2020). & $\begin{array}{l}\text { A concentração de pepsina na saliva é } \\
\text { consideravelmente maior no grupo com } \\
\text { pepsina positiva }\end{array}$ & $\begin{array}{c}\text { A pepsina favorece aos danos no DNA } \\
\text { das células epiteliais laríngeas e estão } \\
\text { presentes na patogênese dos PPVs. }\end{array}$ \\
\hline $\begin{array}{c}\text { Necessidades não atendidas no } \\
\text { tratamento da doença do refluxo } \\
\text { gastroesofágico }\end{array}$ & Dickman R, et al. (2015). & $\begin{array}{c}\text { O tratamento antirrefluxo visa aliviar os } \\
\text { sintomas referentes a DRGE e melhorar a } \\
\text { qualidade de vida do paciente. }\end{array}$ & $\begin{array}{l}\text { A utilização de IBP não contínuo tem } \\
\text { demonstrado interesse devido às } \\
\text { respostas positivas ao tratamento }\end{array}$ \\
\hline $\begin{array}{c}\text { Apresentação extra-esofágica da } \\
\text { doença do refluxo gastroesofágico: } \\
\text { Atualização de } 2020\end{array}$ & Durazzo M, et al. (2020). & $\begin{array}{l}\text { O teste PII é constantemente usado na } \\
\text { primeira etapa do diagnóstico, já em casos } \\
\text { atípicos a laringoscopia e broncoscopia. }\end{array}$ & $\begin{array}{c}\text { As manifestações relacionadas a DRGE } \\
\text { são complexas. O EGD é útil se } \\
\text { sintomas de alarme estiverem } \\
\text { presentes. }\end{array}$ \\
\hline $\begin{array}{c}\text { Impacto da doença do refluxo } \\
\text { gastroesofágico, imunidade mucosa e } \\
\text { doenças atópicas }\end{array}$ & $\begin{array}{l}\text { Hait EJ e Mcdonald DR } \\
\text { (2019). }\end{array}$ & $\begin{array}{c}\text { Estabelecer uma relação entre DRGE e a } \\
\text { asma, rinossinusite, rinite alérgica, dermatite } \\
\text { alérgica e alergia alimentar. Foi visto que a } \\
\text { DRGE pode induzir mudanças no sistema } \\
\text { imunológico. }\end{array}$ & $\begin{array}{c}\text { A DRGE pode ser precursora de } \\
\text { doenças como dermatite alérgica e } \\
\text { alergia alimentar. Bem como ser } \\
\text { gatilho para exacerbação de outras já } \\
\text { pré-existentes como asma, } \\
\text { rinossinusite, rinite. }\end{array}$ \\
\hline $\begin{array}{c}\text { Doença do Refluxo Laringofaríngeo: } \\
\text { Resultado dos Pacientes Após } \\
\text { Tratamento nas Clínicas de } \\
\text { Otorrinolaringologia }\end{array}$ & Junaid M, et al. (2020). & $\begin{array}{l}\text { Expor os resultados dos tratamentos do } \\
\text { DRLE. Mostrou que o manejo do RFS e RSI } \\
\text { são primordiais para a conclusão de RLF e } \\
\text { auxiliam na clínica de otorrinolaringologia. }\end{array}$ & $\begin{array}{c}\text { RFS e RSI são primordiais para a } \\
\text { conclusão de RLF e auxiliam na clínica } \\
\text { de otorrinolaringologia }\end{array}$ \\
\hline $\begin{array}{l}\text { Tosse Crônica Devido ao Refluxo } \\
\text { Gastroesofágico em Adultos }\end{array}$ & Kahrilas PJ, et al. (2016). & $\begin{array}{c}\text { Objetivou o reconhecimento e a diferenciação } \\
\text { do sintoma de tosse crônica como sintoma } \\
\text { preditor de DRGE. Colocou um a tosse crônica } \\
\text { como forma de avaliação primária e } \\
\text { secundária das manifestações extra } \\
\text { esofágicas da DRGE. }\end{array}$ & $\begin{array}{c}\text { A tosse pode ser tanto um sintoma } \\
\text { primário extra esofágicas da DRGE } \\
\text { como secundário a uma exacerbação } \\
\text { asmática pelo fator imunológico da } \\
\text { DRGE. }\end{array}$ \\
\hline
\end{tabular}




\begin{tabular}{|c|c|c|c|}
\hline Título & Autor / Ano & Objetivos / Resultados & Conclusão \\
\hline $\begin{array}{l}\text { Refluxo gastroesofágico em pacientes } \\
\text { com rinossinusite crônica investigados } \\
\text { com impedância multicanal - pHmetria }\end{array}$ & Katle EJ, et al. (2017). & $\begin{array}{c}\text { Correlacionar a presença de DRGE e } \\
\text { rinossinusite crônica como sintoma extra } \\
\text { esofágico. Os pacientes com rinossinusite } \\
\text { crônica que tiveram mais queixas de refluxo } \\
\text { gastroesofágico em relação aos que não tem a } \\
\text { rinossinusite. }\end{array}$ & $\begin{array}{c}\text { A presença de rinossinusite crônica } \\
\text { pode ser considerada um fator de pior } \\
\text { prognóstico nos pacientes portadores } \\
\text { de DRGE. }\end{array}$ \\
\hline $\begin{array}{c}\text { Associação de refluxo } \\
\text { gastroesofágico e rinossinusite } \\
\text { crônica: revisão sistemática e meta- } \\
\text { análise }\end{array}$ & Leason SR, et al. (2017). & $\begin{array}{l}\text { Paciente com rinossinusite crônica apresenta } \\
\text { maior dominância de H. pylori intranasal e } \\
\text { refluxo ácido que indivíduos sem rinossinusite } \\
\text { crônica. Além de maior incidência de SRC em } \\
\text { pacientes com DRGE. }\end{array}$ & $\begin{array}{l}\text { Os médicos devem estar cientes da } \\
\text { relação entre a rinossinusite crônica e a } \\
\text { doença do refluxo gastroesofágico. }\end{array}$ \\
\hline $\begin{array}{l}\text { Refluxo laringofaríngeo: um } \\
\text { gerenciamento de algoritmos de } \\
\text { última geração para médicos da } \\
\text { atenção primária }\end{array}$ & Lechien JR, et al. (2020). & $\begin{array}{l}\text { O algoritmo prático para organizar o refluxo } \\
\text { laringofaríngeo em medicina primária. }\end{array}$ & $\begin{array}{l}\text { A confiança desse algoritmo deve ser } \\
\text { avaliada em estudos futuros. É útil o } \\
\text { estudo de um pepetest para o } \\
\text { diagnóstico no consultório. }\end{array}$ \\
\hline $\begin{array}{l}\text { Características perceptivas, } \\
\text { aerodinâmicas e acústicas das } \\
\text { alterações vocais em pacientes com } \\
\text { doença do refluxo laringofaríngeo }\end{array}$ & Lechien JR, et al. (2019). & $\begin{array}{c}\text { Determina a investigação das mudanças na } \\
\text { característica da voz em pacientes com RLF } \\
\text { em relação aos participantes saudáveis e } \\
\text { objetiva o trato entre os achados na } \\
\text { videolaringoestroboscopia e os níveis } \\
\text { acústicos. }\end{array}$ & $\begin{array}{l}\text { O estudo indica a associação entre RLF } \\
\text { e as mudanças nas características da } \\
\text { voz. Doentes com essa patologia têm } \\
\text { mais dificuldades na voz em relação às } \\
\text { pacientes saudáveis. O edema das } \\
\text { pregas vocais no avanço da rouquidão } \\
\text { está associado à patologia de RLF. }\end{array}$ \\
\hline $\begin{array}{c}\text { O refluxo ácido gastroesofágico } \\
\text { noturno patológico sobre uma série } \\
\text { pHmétrica }\end{array}$ & Nour E, et al. (2018). & $\begin{array}{c}\text { Indicar a periodicidade da DRGE noturno na } \\
\text { pHmetria esofágica de } 24 \text { horas em doentes } \\
\text { com patologias digestivas e extradigestivas, } \\
\text { além de estimar a clínica e a pHmetria } \\
\text { noturna. }\end{array}$ & $\begin{array}{c}\text { O refluxo noturno está relacionado ao } \\
\text { exame de } 24 \text { horas. O período noturno } \\
\text { é caracterizado por episódios mais } \\
\text { longos de refluxo e menos número de } \\
\text { episódios. }\end{array}$ \\
\hline
\end{tabular}




\begin{tabular}{|c|c|c|c|}
\hline Título & Autor / Ano & Objetivos / Resultados & Conclusão \\
\hline $\begin{array}{c}\text { Erosão dentária na doença do refluxo } \\
\text { gastroesofágico. Uma revisão } \\
\text { sistemática }\end{array}$ & Picos A, et al. (2018). & $\begin{array}{l}\text { O objetivo deste estudo é analisar na literatura } \\
\text { dos últimos } 10 \text { anos que correlaciona erosão } \\
\text { dentária com RGE. Com a finalidade de } \\
\text { analisar as diferenças entre o risco e a } \\
\text { frequência de erosão dentária. }\end{array}$ & $\begin{array}{l}\text { Os estudos atuais afirmam relação } \\
\text { entre erosão dentária e o DRGE, } \\
\text { mesmo que a incidência entre os } \\
\text { autores varie. Sendo também a causa } \\
\text { primária de outras patologias } \\
\text { odontológicas. }\end{array}$ \\
\hline $\begin{array}{l}\text { Incidência e padrão de erosão } \\
\text { dentária em pacientes com doença do } \\
\text { refluxo gastroesofágico }\end{array}$ & $\begin{array}{l}\text { Ramachandran A, et al. } \\
\text { (2017). }\end{array}$ & $\begin{array}{l}\text { O estudo é conduzido para analisar e avaliar a } \\
\text { incidência e o padrão de erosão dentária e } \\
\text { RGE. Os resultados deste estudo afirmam que } \\
\text { a incidência de erosão dentária é maior em } \\
\text { quem tem DRGE em relação aos demais. }\end{array}$ & $\begin{array}{c}\text { Problemas odontológicos como erosão } \\
\text { dentária fazem parte dos sintomas } \\
\text { extraesofágicos da DRGE e este ainda } \\
\text { pode propiciar ao aparecimento de } \\
\text { outras complicações da arcada dentária } \\
\text { quando não diagnosticada e tratada de } \\
\text { forma devida. }\end{array}$ \\
\hline $\begin{array}{l}\text { Relação entre rinossinusite crônica e } \\
\text { refluxo gastroesofágico em adultos: } \\
\text { revisão sistemática }\end{array}$ & Sella GCP, et al. (2017). & $\begin{array}{l}\text { Relacionar a presença da DRGE e a } \\
\text { rinossinusite crônica. Constatou que há fatores } \\
\text { de risco em comum para as duas doenças e } \\
\text { que não é incomum a presença de ambas as } \\
\text { doenças nos pacientes. }\end{array}$ & $\begin{array}{l}\text { Apesar de haver uma correlação das } \\
\text { doenças, ainda faltam estudos } \\
\text { controlados com número significativo de } \\
\text { pacientes para confirmar essa hipótese. }\end{array}$ \\
\hline $\begin{array}{l}\text { Laringite de refluxo: correlação entre } \\
\text { os achados dos sintomas e a } \\
\text { laringoscopia indireta }\end{array}$ & Silva CE, et al. (2015). & $\begin{array}{l}\text { Tinha por objetivo avaliar a correlação entre os } \\
\text { sintomas de refluxo e os achados da } \\
\text { laringoscopia indireta. Constatou que é } \\
\text { possível observar na semiologia a presença } \\
\text { de alterações na laringoscopia que levam a } \\
\text { suspeita de sintomas de refluxo. }\end{array}$ & $\begin{array}{c}\text { Presença de alterações da } \\
\text { laringoscopia podem ser os primeiros } \\
\text { achados semiológicos que levantam a } \\
\text { suspeita de DRGE e seu conhecimento } \\
\text { se faz importante para um diagnóstico e } \\
\text { tratamento precoces. }\end{array}$ \\
\hline $\begin{array}{l}\text { Fundoplicatura sem incisão transoral } \\
\text { eficaz na eliminação de sintomas de } \\
\text { DRGE em respondedores parciais à } \\
\text { terapia com inibidor de bomba de } \\
\text { prótons aos } 6 \text { meses: ensaio clínico } \\
\text { randomizado }\end{array}$ & Trad KS, et al. (2015). & $\begin{array}{l}\text { Analisar as repercussões da fundoplicatura } \\
\text { como tratamento da DRGE em pacientes que } \\
\text { foram refratários à terapia medicamentosa. } \\
\text { Foi visto que pacientes nos traços TIF e PPI } \\
\text { apresentaram taxas semelhantes de } \\
\text { normalização do pH esofágico distal. }\end{array}$ & $\begin{array}{c}\text { A Fundoplicatura como uma } \\
\text { possibilidade terapêutica alternativa } \\
\text { principalmente em casos refratários ao } \\
\text { tratamento medicamentoso. }\end{array}$ \\
\hline
\end{tabular}




\begin{tabular}{|c|c|c|c|}
\hline Título & Autor / Ano & Objetivos / Resultados & Conclusão \\
\hline $\begin{array}{c}\text { Extraesophageal Symptoms and } \\
\text { Diseases Attributed to GERD: Where } \\
\text { is the Pendulum Swinging Now? }\end{array}$ & Vaezi MF, et al. (2018). & $\begin{array}{l}\text { Objetivou traçar os achados recentes de } \\
\text { pesquisas sobre manejo da DRGE para } \\
\text { coletar as informações mais relevantes }\end{array}$ & $\begin{array}{l}\text { A medicamentosa empírica com IBP`s } \\
\text { por 6-8 semanas pode ajudar na } \\
\text { avaliação da associação entre refluxo e } \\
\text { sintomas extraesofágicos. A } \\
\text { fundoplicatura cirúrgica não deve ser } \\
\text { feita nos pacientes que com sintomas } \\
\text { extra esofágicos que não respondem à } \\
\text { terapia agressiva com IBP com exceção } \\
\text { de alteração anatômica. }\end{array}$ \\
\hline $\begin{array}{c}\text { Fatores de risco associados a } \\
\text { manif estações orais e impacto na } \\
\text { saúde bucal da doença do refluxo } \\
\text { gastroesofágico: um estudo } \\
\text { transversal multicêntrico no Paquistão }\end{array}$ & Warsi I, et al. (2019). & $\begin{array}{c}\text { Reconhecer as alterações orais de tecido mole } \\
\text { e duro em doentes com DRGE e analisar } \\
\text { essas modificações orais como índices para } \\
\text { avaliar a DRGE e sua magnitude. }\end{array}$ & $\begin{array}{l}\text { Doentes com a DRGE e erosão } \\
\text { dentária contém sintomas orais mais } \\
\text { graves que aqueles pacientes com } \\
\text { DRGE sem erosão dentária. }\end{array}$ \\
\hline $\begin{array}{c}\text { Doença do refluxo gastroesofágico: } \\
\text { uma causa da disfunção da tuba } \\
\text { auditiva na apneia obstrutiva do sono }\end{array}$ & Yan S, et al. (2020). & $\begin{array}{l}\text { Objetiva explorar o ef eito da DRGE na função } \\
\text { da tuba auditiva em pacientes com SAOS. Foi } \\
\text { constatado por meio da alta taxa de } \\
\text { concomitância em pacientes com AOS, a } \\
\text { DRGE pode ser um importante fator de } \\
\text { associação da disfunção da tuba auditiva em } \\
\text { pacientes com SAOS. }\end{array}$ & $\begin{array}{c}\text { A DRGE deve ser incluída como } \\
\text { hipótese diagnóstica quando se trata de } \\
\text { disfunções tubárias e durante a sua } \\
\text { investigação e tratamento deve atentar } \\
\text { para outros problemas secundários } \\
\text { acarretados pela disfunção com forma } \\
\text { de prevenir problemas irreversíveis. }\end{array}$ \\
\hline $\begin{array}{l}\text { Conhecimento da doença do refluxo } \\
\text { laringofaríngeo entre } \\
\text { otorrinolaringologistas de hospitais 3A } \\
\text { em Pequim }\end{array}$ & Zhang J, et al. (2019). & $\begin{array}{l}\text { O objetivo deste estudo foi avaliar o } \\
\text { conhecimento sobre a DRLE entre } \\
\text { otorrinolaringologistas de hospitais em } \\
\text { Pequim. Foi constatado que há uma } \\
\text { necessidade de promover cursos de } \\
\text { atualização e aprimoramento do conhecimento } \\
\text { dos profissionais sobre a DRLE. }\end{array}$ & $\begin{array}{c}\text { Há um relativa defasagem de } \\
\text { conhecimento acerca da patologia e } \\
\text { sobre o diagnóstico e tratamento } \\
\text { O conhecimento sobre a DRLE é } \\
\text { fundamental para o diagnóstico e } \\
\text { tratamento precoce. }\end{array}$ \\
\hline
\end{tabular}

Fonte: Coelho JF, et al., 2021. 
A DRGE é uma doença crônica de alta prevalência, sendo relatados sintomas relacionados a ela pelo menos uma vez por mês em $44 \%$ da população adulta dos Estados Unidos da América (EUA), de acordo com o estudo de base populacional, que também mostrou discreta prevalência em homens, além de correlacionar com fatores de risco como: obesidade, anormalidades motoras, idade acima de 50 anos, tabagismo e etilismo. Os sintomas extra-esofágicos causados pela doença têm cada vez mais seu impacto reconhecido pelos otorrinolaringologistas. Dentre as manif estações extra-esofágicas otorrinolaringológicas, as mais comuns são: tosse crônica e laringite. Outras manif estações menos frequentes também podem estar presentes, tais como: sinusite crônica, rinite crônica e apneia obstrutiva do sono (ANTUNES C, et al., 2021; DICKMAN R, et al., 2015).

A tosse crônica isolada é um dos achados extra-esofágicos mais frequentes quando os demais sintomas gastrointestinais estão ausentes, o que dificulta o diagnóstico. A principal hipótese desse sintoma é o mecanismo de reflexo vagal mediado pelo refluxo esofágico -traqueobrônquico que leva a uma microaspiração de material gástrico refluído no trato traqueobrônquico (DURAZZO M, et al., 2020).

O sintoma da tosse crônica relacionada a doença do refluxo apresenta resposta significativa na terapêutica com o uso de omeprazol durante 8 a 12 semanas. Nos casos de resistência pode ser adicionado ao esquema terapêutico um antagonista do receptor $\mathrm{H} 2$ da histamina e/ou baclofeno. Esse último age inibindo o relaxamento transitório do Esfíncter Esofágico Inferior (EEI) e em um estudo realizado se mostrou $100 \%$ eficaz na melhora da tosse crônica. Quando não ocorre nenhuma melhora é sugestivo que outros fatores estejam relacionados com a tosse crônica e as mudanças comportamentais são muito importantes para obter um bom resultado, incluindo modificação da dieta e também elevação da cabeceira da cama para evitar regurgitação (VAEZI MF, et al., 2018; KAHRILAS PJA, et al., 2016).

Os sinais e sintomas laríngeos crônicos associados à DRGE são frequentemente chamados de laringite por RLF. Estima-se que 50-60\% das laringites crônicas e dores de garganta de difícil tratamento podem estar relacionadas à DRGE. Os sinais clínicos na laringite relacionada ao refluxo geralmente incluem eritema cricóide posterior, eritema / edema das cordas vocais e eritema / edema das aritenóides. As queixas mais comuns são limpeza de garganta, tosse persistente, globus e rouquidão e se ap resentam principalmente como eventos de refluxo gasoso, ereto e diurno (SILVA CE, et al., 2015).

Como o RLF muitas vezes pode ter como gênese maus hábitos alimentares e o estresse, é imperativo a mudança de hábitos de vida. Dessa forma, na prática clínica o tratamento utilizado inclui dieta, IBP e medicação com alginato para abranger todos os tipos de RLF (LECHIEN JR, et al., 2020).

A Apneia Obstrutiva do Sono (AOS) é um distúrbio muito tratado nos consultórios otorrinolaringológicos e consiste em obstruções repetitivas completas ou parciais (hipopneia) das vias aéreas superiores, e também, de esforço respiratório associado, causando despertares repetitivos e fragmentação do sono (YAN S, et al., 2020).

Pesquisas demonstram que, com algumas pessoas, pode existir relação da DRGE com AOS, pois o refluxo ácido também pode causar inflamação e edema da laringe, que por sua vez pode piorar a obstrução das vias aéreas superiores e também pode causar contrações traqueais que podem piorar os episódios de AOS. $O$ contrário também pode ocorrer, já que o aumento da excitação em pacientes com $A O S$, junto com a redução da eficiência do sono, pode desencadear o relaxamento do EEI e promover o refluxo gástrico (YAN S, et al., 2020).

No entanto, ainda há controvérsias sobre a associação da AOS e DRGE. Pesquisas feitas demonstraram que $38,9 \%$ dos pacientes que apresentavam AOS estavam associadas à DRGE. O tratamento nesses casos é através da fundoplicatura laparoscópica de Nissen (LNF), tendo resultados positivos nos sintomas da D RGE e da AOS. A explicação para tal melhora pode ser através de 2 hipóteses: a primeira é que a LNF reduz a exposição do ácido no esôfago, o que diminui a inflamação e edema da laringe e alivia a obstrução das vias aéreas superiores e a apneia; a segunda hipótese é que a fundoplicatura pode cortar e destruir a distribuição das terminações nervosas sensoriais na superfície do esôfago, diminuindo o reflexo do nervo vago, mesmo se o refluxo ácido persistir (WU ZH, et al., 2019; BASOGLU OK, et al., 2015).

REAC | Vol. 41 | DOI: https://doi.org/10.25248/REAC.e9379.2021 
Além da AOS, a Disfunção da Tuba Auditiva (DTE) também pode estar relacionada aos eventos de DRGE e AOS e está associada a uma alta ocorrência de eventos de refluxo que podem afetar a sua patogênese. Além dessa patologia, o bloqueio ou abertura retardada da tuba auditiva estão presentes em muitos pacientes com AOS. Estudos apontam que a frequência de DTE é maior em pacientes com DRGE isoladamente do que associado à AOS, pois o refluxo do conteúdo estomacal pode bloquear as trompas de Eustáquio aumentando o risco de causar uma subsequente otite média. Nesses casos, pode ser recomendado o uso de medicamento anti-refluxo para melhora da sensação de pressão ref ratária nos ouvidos (YAN S, et al., 2020).

A relação entre a rinossinusite crônica em pacientes com DRGE e RLF não é concreta. Assim, estudos apontam que o tratamento de episódios frequentes de DRGE pode ter um efeito positivo na rinite e rinossinusite em geral. Duas hipóteses são consideradas: a primeira é a exposição direta da mucosa nasal e nasofaríngea ao ácido gástrico, causando inflamação da mucosa e comprometimento da depuração mucociliar, podendo causar obstrução dos óstios sinusais e infecções recorrentes; a segunda é uma relação mediada pelo nervo vago, mecanismo já comprovado nas vias aéreas inferiores e na mucosa nasal de pacientes com rinite, mas não em pacientes com RSC (LEASON SR, et al., 2017).

A disfunção do sistema nervoso autônomo, considerada na segunda hipótese, pode levar ao edema e inflamação nasossinusal e consequente bloqueio dos óstios. Nesse contexto, a presença de $\mathrm{H}$. pylori pode ser um marcador de refluxo nasof aringe, afinal o principal reservatório de $\mathrm{H}$. pylori é no estômago (HAIT EJ e MCDONALD DR., 2019; SELLA GCP, et al., 2017).

Os testes diagnósticos, como endoscopia, monitoramento de ph e laringoscopia tem baixa sensibilidade e especificidade; não há nenhum teste que vincule qualquer sintoma extra-esofágico com DRGE. Entretanto, podem auxiliar na confirmação ou exclusão do diagnóstico. As diretrizes atuais sugerem que a terapêutica da DRGE com apresentação de sintomas típicos (azia e regurgitação) seja de forma empírica. No entanto, quando associada a manifestações atípicas/extra esofágicas, a terapia empírica não é a primeira escolha, devendo antes passar por uma avaliação da função esofágica (CESÁRIO S, et al., 2018; VAEZI MF, ET AL., 2018).

Os inibidores da bomba de prótons (PPIs) e os antagonistas do receptor de histamina tipo 2 (H2RAs) são os escolhidos para o tratamento da DRGE, sendo os H2RAs de menor potência. Em alguns tipos de DRGE como a esofagite erosiva avançada (EE) e doença do refluxo não erosiva (NERD), o tratamento com IBP, nesses casos, não é eficaz. Além disso, estudos mostram que o tratamento com PPIs para sintomas atípicos e extra-esofágicos (laríngeos, faríngeos e pulmonares) também não apresentaram respostas positivas em relação ao placebo. O tratamento com IBP, tanto da DRGE isolada quanto associada a manifestações extraesofagicas, deve ser avaliado com muita cautela, afinal não apresenta respostas signific ativas em algumas situações e pode aumentar o risco dos ef eitos adversos (CHUANG TW, et al., 2017; DICKMAN R, et al., 2019).

Apesar disso, a resolução terapêutica vai depender de cada paciente e de seus sintomas extra-esofágicos relacionados com a DRGE, podendo ser por meio medicamentoso, através de IBP, ou de forma cirúrgica, que é indicada para pacientes que abandonam o tratamento, seja por falta de adesão ou pelos ef eitos colaterais ou por ser a longo prazo, e também, pacientes com hérnia de hiato grande. Os tipos de cirurgia adequados são: a fundoplicatura anterior laparoscópica $180^{\circ}\left(\operatorname{LAF} 180^{\circ}\right)$; fundoplicatura de Nissen; e a cirurgia bariátrica em pacientes idosos. A fundoplicatura de Nissen é a mais utilizada, sendo considerada padrão ouro em pacientes com DRGE (ANTUNES C, 2021).

Em todas as situações, independentemente de como a doença venha se manifestar e de como o paciente será tratado, a mudança de estilo de vida e modificação da dieta tem importante relevância para a diminuição da exposição ao ácido esofágico distal e consequentemente para a diminuição dos sintomas da DRGE. Essas mudanças consistem em: perda de peso, elevação da cabeceira, evitar alimentação antes de dormir e evitar consumo de chocolate, comidas picantes, álcool e tabaco. A combinação do diagnóstico precoce junto ao tratamento imediato e adesão do paciente é necessária para uma resposta positiva na resolução da DRGE, na prevenção de complicações como esofagite e adenocarcinoma esofágico e na melhora da qualidade de vida do indivíduo (ANTUNES C, et al., 2021; CHUANG TW, et al., 2017). 


\section{CONSIDERAÇÕES FINAIS}

A DRGE é uma patologia comum na otorrinolaringologia e diretamente relacionada com os hábitos de vida. Sua ocorrência se deve a um distúrbio do esfíncter esofágico inferior, que leva a três tipos de manifestações: típica, atípica e extra esofágica; sendo os mais comuns a tosse, azia, regurgitação e esofagite. $O$ tratamento se baseia no uso de IBP que associado a mudança no estilo de vida e dieta torna a terapêutica positiva. Apesar de ser uma doença comum, ainda é importante e pertinente a realização de mais estudos sobre o tema, principalmente com relação à uma abordagem mais eficiente no tratamento dos indivíduos que possibilita melhor evolução clínica sem maiores complicações e prejuízos.

\section{REFERÊNCIAS}

1. AKINOLA MA, et al. Gastroesophageal reflux disease: prevalence and Extraesophageal manifestations among undergraduate students in South West Nigeria. BMC Gastroenterology, 2020;20:160.

2. ANTUNES C, et al. Doença do refluxo gastroesofágico. National Library of Medicine, 2021;1-8.

3. AZZAM RS. Are the persistent sym ptoms to proton pump inhibitor therapy due to refractory gastroesophageal reflux disease or to other disorders?. Arq Gastroenterol, 2018;55(1):85-91.

4. BASOGLU OK, et al. Síndrome da apnéia obstrutiva do sono e doença do refluxo gastroesofágico: a importância da obesidade e gênero. Respiração do sono, 2015; 19 (2): 585-592.

5. CESÁRIO S, et al. Diagnóstico de DRGE em manifestações típica e atípicas. Acta Biomed, 2018;89 (8-S): 33-39.

6. CHUANG TW, et al. Current status of gastroesophageal reflux disease: diagnosis and treatment. Acta Gastroenterologia Bélgica, 2017;80(3):396-404.

7. COSSÍO SS, et al. La búsqueda del Grial: una carrera por la supresiónácida. Revista de Gastroenterología de México, 2019;84(3):344-356.

8. DAI FY, et al. Associação de pepsina e danos de DNA no refluxo laringofaríngeo relacionado a pólipos de prega. American Journal of Otolaryngology, 2020; 10268.

9. DICKMAN R, et al. Unmet Needs in the Treatment of Gastroesophageal Reflux Disease. Journal of Neurogastroenterology and Motility, 2015;21(3): 309-219.

10. DURAZZO M, et al. Extra-Esophageal Presentation of Gastroesophageal Reflux Disease: 2020 Update. Journal of Clinical Medicine, 2020;1-21.

11. HAIT EJ, MCDONALD DR. Impact of Gastroesophageal Reflux Disease Mucosal Immunity and Atopic Disorders. Clin Rev Allergy Immunol, 2019;57(2):213-225.

12. JUNAID M, et al. Doença do Refluxo Laringofaríngeo: Resultado dos Pacientes Após Tratamento nas Clínicas de Otorrinolaringologia. Cureus, 2020;12 (12): e12195.

13. KAHRILAS PJ, et al. Tosse Crônica Devido ao Refluxo Gastroesofágico em Adultos. CHEST Journal, 2016 ; 150 (6): 1341-1360.

14. KATLE EJ, et al. Gastro-oesophageal reflux in patients with chronic rhino-sinusitis investigated with multichannel impedance - $\mathrm{pH}$ monitoring. Rhinology, 2017;55(1):27-33.

15. LEASON SR, et al. Association Of Gastro-oesophageal reflux and chronic rhinosinusitis: systematic reviewand metaanalysis. Rhinology. 2017;55(1):3-16.

16. LECHIEN JR, et al. Laryngopharyngeal Reflux: A State-of-the-Art Algorithm Management for Primary Care Physicians. Journal of Clinical Medicine, 2020;9(11):3618.

17. LECHIEN JR, et al. Perceptual, Aerodynamic, and Acoustic Characteristics of Voice Changes in Patients with Laryngopharyngeal Reflux Disease. Ear Nose \& Throat Journal, 2019; 98(6):E44-E50.

18. NOUR E, et al. Le reflux gastro-oesophagien acide nocturne pathologique. a propos d'une série pHmétrique. LA TUNISIE MEDICALE, 2015;93(4):1-5..

19. PICOS A, et al. Dental erosion in gastroesophageal reflux disease. A systematic review. Clujul Med. 2018;91(4):387390.

20. RAMACHANDRAN A, et al. Incidence and Pattern of Dental Erosion in Gastroesophageal Reflux Disease Patients. J Pharm Bio allied Sci. 2017;9 (Suppl 1):S138-S141.

21. SELLA GCP, et al. Relation between chronic rhinosinusitis and gastroesophageal reflux in adults: systematic review. Braz J Otorhinolaryngol. 2017;83(3):356-363.

22. SILVA CE, et al. Reflux Laryngitis: Correlation between the Symptoms Findings and Indirect Laryngoscopy. Int Arch Otorhinolaryngol, 2015;19(3):234-7.

23. TRAD KS, et al. Transoral Incisionless Fundoplication Effective in Eliminating GERD Symptoms in Partial Responders to Proton Pump Inhibitor Therapy at 6 Months: The TEMPO Randomized Clinical Tria. Surgical Innovation, 2015; 22(1): $26-40$.

24. VAEZI MF, et al. Extraesophageal Symptoms and Diseases Attributed to GERD: Where is the Pendulum Swinging Now? Clin Gastroenterol Hepatol. 2018; 16(7):1018-1029.

25. WARSI I, et al. Fatores de risco associados a manifestações orais e impacto na saúde bucal da doença do refluxo gastroesofágico:um estudo transversal multicêntrico no Paquistão. BMJ Open. 2019;9 (3): e021458.

26. YAN S, et al. Gastroesophageal Reflux Disease: A Cause for Eu stachian Tube Dysfunction in Obstructive Sleep Apnea. Ear Nose Throat J, 2020; 4:145561320931219.

27. ZHANG J, et al. Knowledge of laryngopharyngeal reflux disease among otolaryngologists in $3 A$ hospitals in Beijing. Journal of International Medical Research, 2019; 48(3):1-6. 